\title{
Fragilidade ambiental apoiada nas classes de declividade da Ilha de Tauá-Mirim: contribuição aos estudos para criação da RESEX de Tauá-Mirim.
}

\author{
Environmental fragility supported in slope classes of Tauá-Mirim Island: contribution \\ to the studies for the creation of RESEX Tauá-Mirim.
}

RABELO, S. S. L. ${ }^{1}$; FEITOSA, A. C. ${ }^{2}$

laianessr@yahoo.com.br

\begin{abstract}
Resumo
Inserida no complexo e dinâmico ambiente costeiro do município de São Luís e situada nas proximidades do setor industrial, a Ilha de TauáMirim reúne elementos importantes na compreensão da fragilidade ambiental. A abordagem leva em consideração aspectos físicos e socioeconômicos que contextualizam a formação e configuração da área de estudo, tendo em vista suas peculiaridades. A partir de uma abordagem sistêmica, utiliza-se a metodologia "fragilidade potencial do meio por classes de declividade" de modo a verificar como as variáveis ambientais se comportam nesse ambiente tão dinâmico.
\end{abstract}

Palavras-chave: Fragilidade Ambiental; Reserva Extrativista; Ilha de Tauá-Mirim

\begin{abstract}
Inserted in the complex and dynamic coastal environment of the city of St. Louis and situated close to the industrial sector, Tauá- Mirim Island brings together key elements in understanding the environmental fragility. The approach takes into account the physical and socioeconomic factors that contextualize the formation and configuration of the study area, taking into view their peculiarities. From a systemic approach, using the methodology "potential fragility of the declivity for classes" in order to verify how environmental variables behave in this very dynamic environment.
\end{abstract}

Keywords: Environmental Fragility; Extractive Reserve; Island Tauá-Mirim

\section{INTRODUÇÃO}

Nas últimas décadas os modelos de urbanização e industrialização das cidades levaram estas a exercer nos seus ambientes naturais uma maior interferência tendo em vista a necessidade de atender novas demandas. Essas interferências têm provocado alterações diretas no equilíbrio dos sistema ambientais, surgindo assim a necessidade de planejar o espaço de modo a minimizar a interferência do homem no ambiente, tornando-se de extrema relevância a elaboração de programas de desenvolvimento econômico-social e a criação de redutos ecológicos protegidos.

Em nível nacional, a interação homem-ambiente já ocasionou profundas modificações na morfologia da paisagem e em seus processos, o que tem gerado inúmeras discussões tanto na avaliação da abrangência das alterações, quanto na tentativa de encontrar estratégias para amenizar os drásticos prejuízos.

No Maranhão, Estado possuidor do segundo maior e mais diversificado segmento do litoral brasileiro, ainda não se tem uma avaliação da abrangência desses impactos sobre seu 
território. No entanto, já são evidentes as modificações resultantes de atividades como a agroindústria e a transformação de áreas em corredor de exportação.

Na Ilha do Maranhão, em particular no município de São Luís, as três últimas décadas foram marcadas por fortes mudanças ambientais, decorrentes principalmente do crescimento urbano-industrial que ocasionou a diminuição dos recursos naturais, potencializada a partir da década de 1980 com a implantação do Consócio ALCOA, ALCAN e BILLITON (ALUMAR) e da Companhia Vale do Rio Doce (CVRD).

Inserida no complexo e dinâmico ambiente costeiro do município de São Luís e situada nas proximidades do setor industrial encontra-se a ilha de Tauá-Mirim, cujo território é ocupado por populações tradicionais distribuídas em seis povoados que ainda conservam um modelo particular de interação com o meio, inclusive motivando estudos para a criação de uma unidade de conservação.

A Ilha de Tauá-Mirim se localiza na porção sudoeste da Ilha do Maranhão, delimitada

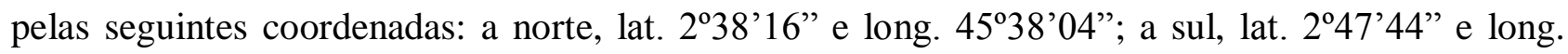

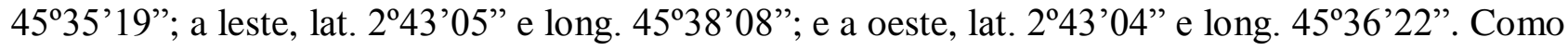
limites geográficos possui a norte e a oeste a Baía de São Marcos; a leste o Estreito dos Coqueiros; e a sul a Ilha de Tauá-Redondo. Sob administração política do município de São Luís, a Ilha faz parte da área de abrangência da zona rural, ocupando uma extensão aproximada de $290.117,86$ m² $^{2}$

Com o propósito de investigar a estrutura da paisagem da Ilha de Tauá-Mirim, procedeu-se a elaboração do presente estudo sob o prisma da abordagem sistêmica, em que a interrelação dos componentes - relevo, solo, cobertura vegetal, uso/ocupação e pluviosidade - são analisados considerando suas respectivas características na definição do grau de fragilidade que servem como subsídio ao planejamento do uso racional.

$\mathrm{Na}$ análise da fragilidade ambiental, as variáveis são tratadas de forma integrada, o que possibilita o diagnóstico dos diferentes níveis de fragilidade dos ambientes naturais, permitindo a avaliação das potencialidades e restrições. Nessa interação, o grau de fragilidade apresentado por cada componente do sistema se mostra de grande importância no estudo do conjunto, possibilitando ao gestor traçar medidas de intervenção técnica e de planejamento ambiental e territorial.

\section{METODOLOGIA}

A teoria sistêmica emerge na pesquisa diante da necessidade de uma abordagem que permita um estudo dos componentes ambientais - físicos e bióticos - de maneira integrada, pois a analise da fragilidade do meio proposta por Ross (1994) fundamenta-se no princípio de que a natureza apresenta funcionalidade intrínseca entre seus componentes físicos e bióticos, exigindo um 
estudo integrado dos componentes do estrato geográfico os quais, analisados e inter-relacionados, geram um produto analítico-sintético que retrata a situação da área de estudo.

As atividades de pesquisa foram desenvolvidas em etapas distintas, iniciadas com a digitalização e interpretação dos dados cartográficos das cartas da DSG (1980), folhas 36, 37, 43, 44, 50, 51, 55 e 56 na escala de 1:10.000, com equidistância das curvas de nível em $5 \mathrm{~m}$. Posteriormente, foram feitas observações de campo para coleta de dados fotográficos, realização de entrevistas, delimitação da área de estudo, confirmação das informações de laboratório e coleta de pontos com GPS.

Para processamento dos dados utilizou-se o software Arc Gis 9.3, de onde foram geradas as cartas temáticas, sendo que algumas particularidades devem ser ressaltadas como a da carta de pluviosidade em que se utilizou o processo de interpolação espacial e da carta de uso e ocupação/cobertura vegetal em que foi utilizada a imagem de satélite worldview-2 de 2010 na validação dos dados.

Posteriormente, o trabalho seguiu na análise e caracterização de cada um dos componentes ambientais (relevo, solo, uso ocupação/cobertura vegetal e pluviosidade) e identificação do grau de fragilidade de cada uma das variáveis dos componentes.

O modelo de classes de declividade foi elaborado apoiado nos intervalos dos estudos de capacidade de uso/aptidão agrícola, associados aos de valores críticos da geotécnica, e foi proposto na tentativa de melhor identificar a fragilidade nos ambientes naturais.

$\mathrm{Na}$ análise da fragilidade é necessário que os conhecimentos das variáveis que dão origem às cartas intermediárias - declividade, solo, uso e ocupação/cobertura vegetal e pluviosidade $^{1}$ - sejam avaliados de forma integrada. Essa inter-relação das variáveis para a classificação da fragilidade segue, segundo Ross (1994, p. 69), uma associação de dígitos arábicos onde cada um dos números representa uma condicionante e um determinado peso nos intervalos de 1 a 5 , do mais fraco ao mais forte.

A carta de fragilidade como produto da correlação das variáveis relacionadas acima deve ser analisada segundo critérios pré-estabelecidos pelo modelo. No caso em estudo, a associação dos pesos para a determinação do grau de fragilidade teve como primeiro digito da combinação a variável relacionada ao grau de declividade, os demais seguiram a hierarquização definida pelos pesos.

\footnotetext{
${ }^{1}$ Segundo Sporl (2001), os níveis hierárquicos dos comportamentos da variável pluviosidade só foram definidos por Ross (2000).
} 


\section{RESULTADOS E DISCUSSÃO}

3.1 Uma experimentação metodológica do modelo de fragilidade ambiental apoiado nas classes de declividade

\subsubsection{Classe de declividade}

Em relação à declividade, o modelo leva em consideração os intervalos dos estudos de capacidade de uso/aptidão agrícola associados com aqueles conhecidos como valores críticos da geotécnica, no entanto, os intervalos da carta de declividade da Ilha de Tauá-Mirim foram ajustados tendo como base as particularidades da área estudada, principalmente no que diz respeito às baixas declividades (Quadro 1 / Figura 1). Para analise da variável também foi elaborada a carta Hipsométrica (Figura 2).

Quadro 1. Intervalos de declividade. Fonte: Ross (1994), Bezerra (2011).

\begin{tabular}{|c|c|c|c|}
\hline \multicolumn{2}{|c|}{ Ross (1994) } & \multicolumn{2}{c|}{ Bezerra (2011) } \\
\hline 1 & $<3 \%$ & 2 & 0 a 2\% \\
\hline $2-3$ & $3 \%$ a $6 \%$ & 3 & 2 a $5 \%$ \\
\hline $3-6$ & $6 \%$ a $12 \%$ & 4 & $5-10 \%$ \\
\hline $4-12$ & $12 \%$ a $20 \%$ & 5 & $10-20 \%$ \\
\hline $5-20$ & $20 \%$ a 30\% & & $>20 \%$ \\
\hline $6-30$ & $30 \%$ a $50 \%$ & $50 \%$ & \\
\hline 7 & \multicolumn{2}{|}{5} \\
\hline \multicolumn{4}{|c|}{ Classificação dos pesos adotados: 1.Muito baixa 2.Baixa 3.Média 4 Forte 5. Muito Forte } \\
\hline
\end{tabular}




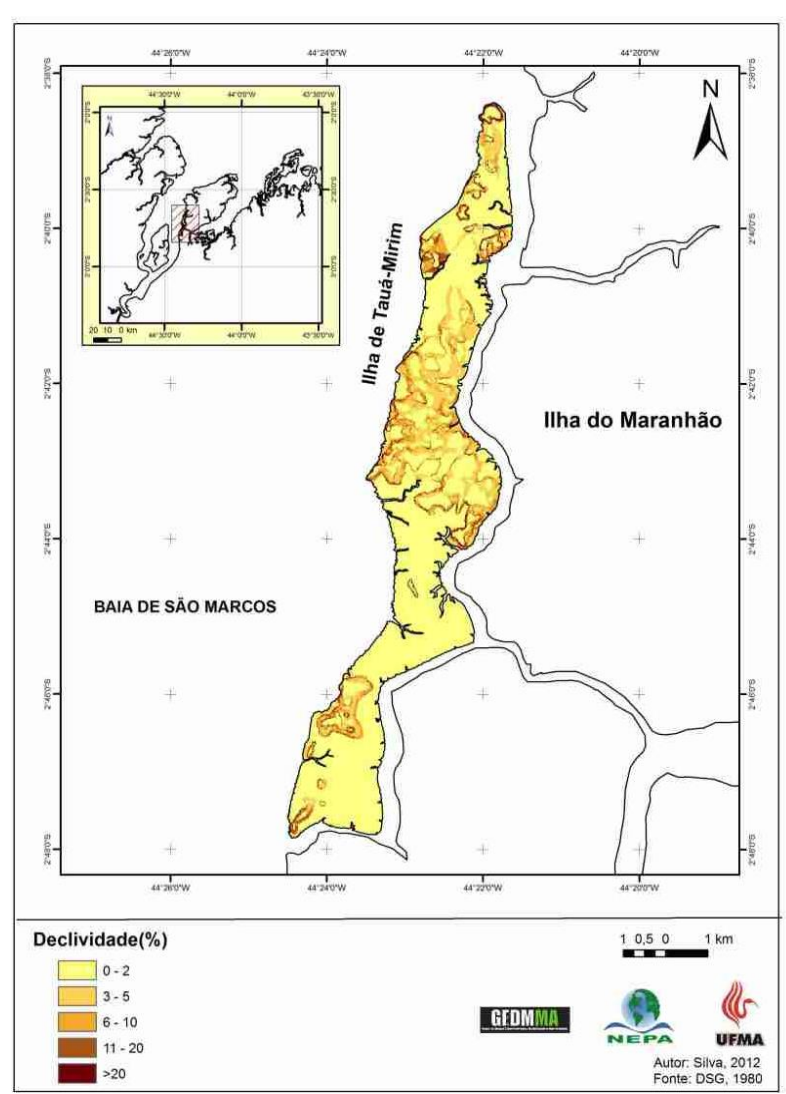

Figura 1. Classes de Declividade Fonte: Silva, S.L

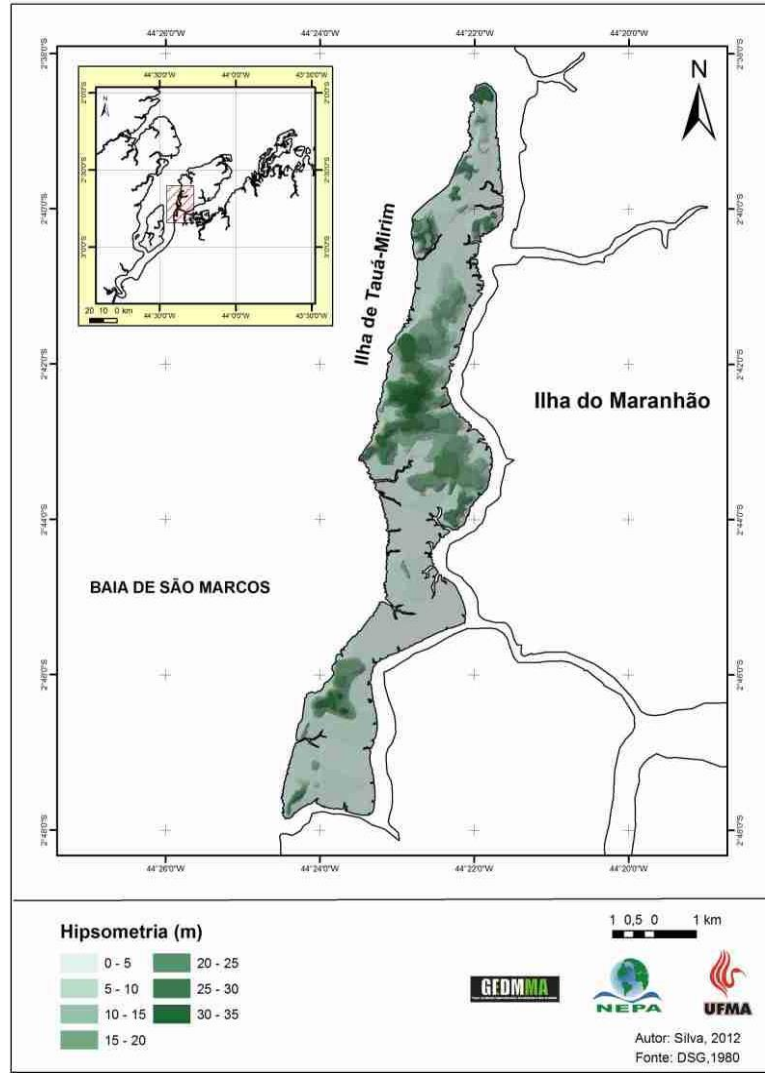

Figura 2. Classes Hipsometrica Fonte: Silva, S.L

3.1.2 Classe de solo

A carta de solo constitui um dos produtos intermediários no processo de produção da carta de fragilidade ambiental. Contudo, é um elemento importante para a análise do conjunto por subsidiar a compreensão das possibilidades de resistência dos materiais superficiais à ação dos agentes modeladores. Para essa variável foram validados os critérios estabelecidos por Ross (1994), que define as classes de fragilidade dessa variável (Quadro 2 / Figura 3).

Quadro 2. Classes de solo. Fonte: Ross, 1994.

\begin{tabular}{|c|c|c|}
\hline $\begin{array}{l}\text { Classes de } \\
\text { fragilidade } \\
\text { do solo }\end{array}$ & Tipos de Solo & Solo da área \\
\hline 1 & $\begin{array}{l}\text { Latossolo roxo; latossolo vermelho escuro e vermelho } \\
\text { amarelo; textura argilosa. }\end{array}$ & - \\
\hline 2 & $\begin{array}{l}\text { Latossolo amarelo e vermelho amarelo; textura } \\
\text { média/argilosa. }\end{array}$ & - \\
\hline 3 & $\begin{array}{l}\text { Latossolo vermelho amarelo; terra roxa; terra bruna; } \\
\text { podzólico vermelho-amarelo; textura média/argilosa. }\end{array}$ & $\begin{array}{l}\text { Solo indiscriminado } \\
\text { de mangue }\end{array}$ \\
\hline 4 & $\begin{array}{l}\text { Podzólico vermelho-amarelo textura média/arenosa; } \\
\text { cambissolos. }\end{array}$ & $\begin{array}{l}\text { Argissolo Vermelho } \\
\text { concressionário }\end{array}$ \\
\hline 5 & $\begin{array}{c}\text { Podzolizados com cascalho; litólicos e areias } \\
\text { quartzosas. }\end{array}$ & $\begin{array}{l}\text { Argissolo Vermelho } \\
\text { Amarelo }\end{array}$ \\
\hline
\end{tabular}




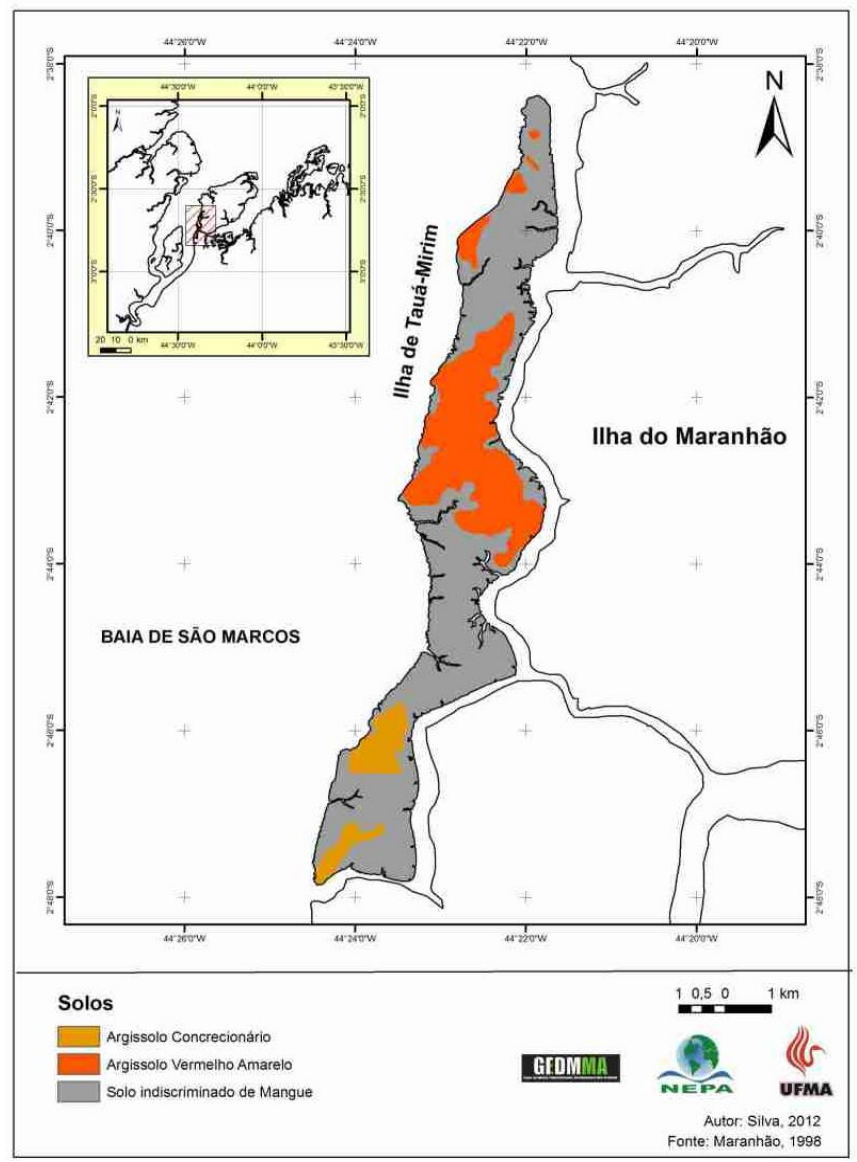

Figura 3. Classes de solos Fonte: Silva, S.L

Para o solo indiscriminado de mangue, identificado na área de estudo e não descrito na metodologia proposta por Ross (1994), foi atribuído o nível 3, em face da natureza inconsolidada do seu material, bem como por ser considerado impróprio para a agricultura devido às fortes limitações que apresenta, excesso de água e sais solúveis e escassez de oxigênio, prejudiciais ao desenvolvimento da maioria dos vegetais.

\subsubsection{Classe de Uso e Ocupação/Cobertura Vegetal}

A classe de uso foi analisada segundo as características observadas pelo pesquisador, pois como relata Sporl (2001), não há uma classificação de uso da terra que seja única e ideal, haja vista as diferentes perspectivas envolvidas no processo de classificação. Cada classificação é feita para atender as necessidades dos usuários.

Os tipos de usos da terra associados à cobertura vegetal compõem a variável que identifica o ponto de rompimento do equilíbrio dinâmico, pois a dinâmica dos processos erosivos está relacionada, em parte, ao grau de proteção que esta condicionante oferece ao solo principalmente contra a perda de material. Assim, o peso é atribuído de acordo com o grau de fragilidade que a variável oferece ao meio, sendo inversamente proporcional ao grau de proteção. 
Para a produção da carta de uso e ocupação/cobertura vegetal (Quadro 3) foram utilizadas imagem de satélite e coleta de dados em campo (Figura 4)

Quadro 3. Classe de Uso/Cobertura Vegetal. Fonte: Adaptado de Ross, 1994.

\begin{tabular}{|c|c|}
\hline Grau de fragilidade & Uso / Cobertura Vegetal \\
\hline 3 & Cobertura Vegetal \\
\hline 4 & Ocupação \\
\hline 5 & Solo Exposto \\
\hline
\end{tabular}

\subsubsection{Classe Pluviométrica}

Para a obtenção do produto-síntese também foi considerada a ação da pluviosidade anual tendo como referências a interpolação dos índices mensurados pela SUDENE nas estações de São Luís, Rosário, São José de Ribamar e São Bento. Porém, devido à pequena extensão da área e às características do relevo, foram considerados somente dois intervalos (Quadro 4 / Figura 5).

Quadro 4. Classes de Pluviosidade. Fonte: Silva, S. L, 2012.

\begin{tabular}{|c|c|}
\hline Classe de fragilidade & Pluviosidade $(\mathrm{mm})$ \\
\hline 4 & $2.192-2.216$ \\
\hline 5 & $2.117-2.240$ \\
\hline
\end{tabular}

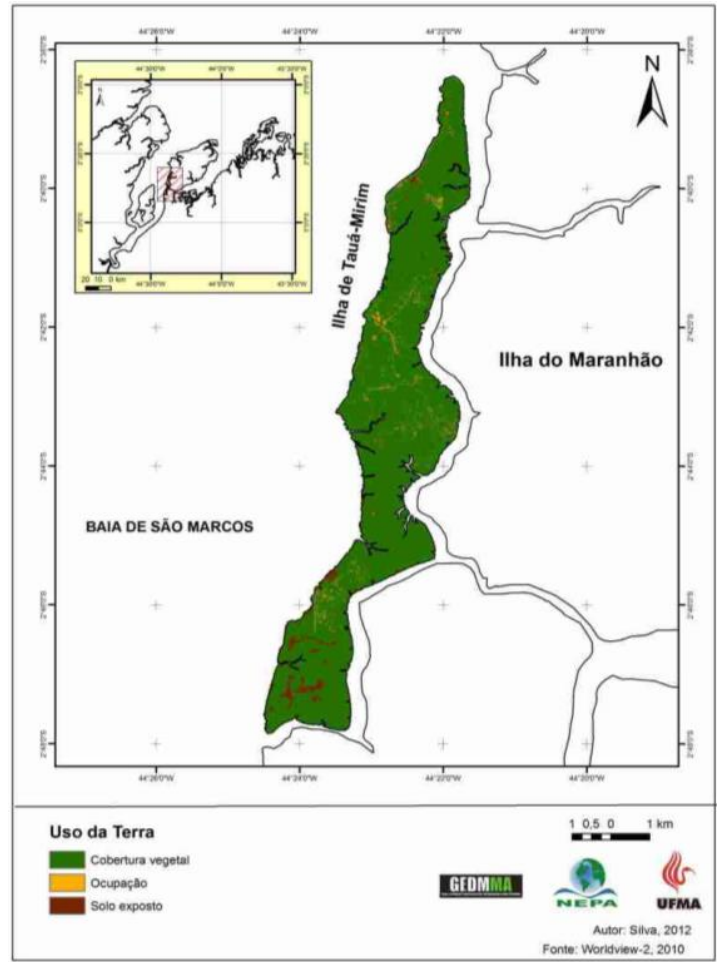

Figura 4.Classe de Usos Fonte: Silva, S.L

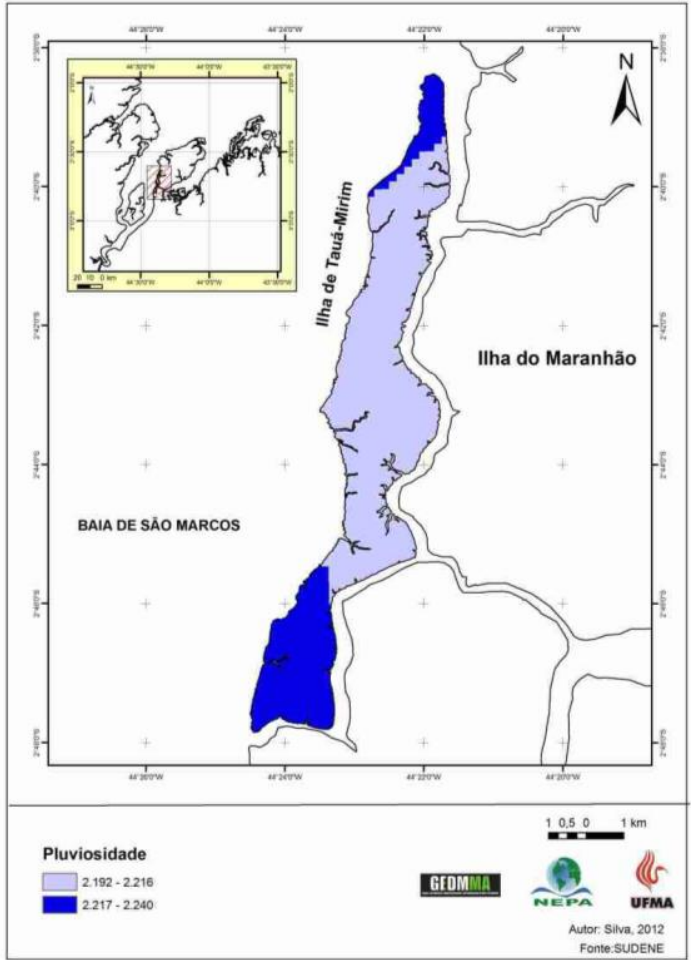

Figura 5 Classes de Pluviosidade Fonte: Silva, S. L 


\subsubsection{Grau de fragilidade da Ilha de Tauá-Mirim}

O produto abaixo identifica e classifica as variáveis com seus respectivos graus de fragilidade. Essas informações constituem parte de um conjunto de componentes que configuram o meio e que se relacionam de maneira dinâmica e sistêmica (Quadro 5) (Figura 6).

Quadro 5. Classes de fragilidade com respectivos pesos para Ilha de Tauá-Mirim. Fonte: Silva,2012

\begin{tabular}{|c|c|c|c|c|}
\hline $\begin{array}{c}\text { Pesos } \\
\text { correspondentes as } \\
\text { classes }\end{array}$ & $35 \%$ & $25 \%$ & $20 \%$ & $20 \%$ \\
\hline Classes & Declividade & Solo & Uso/Cob.Vegetal & Pluviosidade \\
\hline 1 & 0 a $2 \%$ & - & - & - \\
\hline 2 & 2 a $5 \%$ & - & - & - \\
\hline 3 & $5-10 \%$ & $\begin{array}{c}\text { Solo } \\
\text { indiscriminado de } \\
\text { mangue }\end{array}$ & Cobertura Vegetal & - \\
\hline 4 & $10-20 \%$ & $\begin{array}{c}\text { Argissolo } \\
\text { Vermelho } \\
\text { concressionário }\end{array}$ & Ocupação & $2.192-2.216$ \\
\hline 5 & $>20 \%$ & $\begin{array}{c}\text { Argissolo } \\
\text { Vermelho Amarelo }\end{array}$ & Solo Exposto & $2.117-2.240$ \\
\hline
\end{tabular}

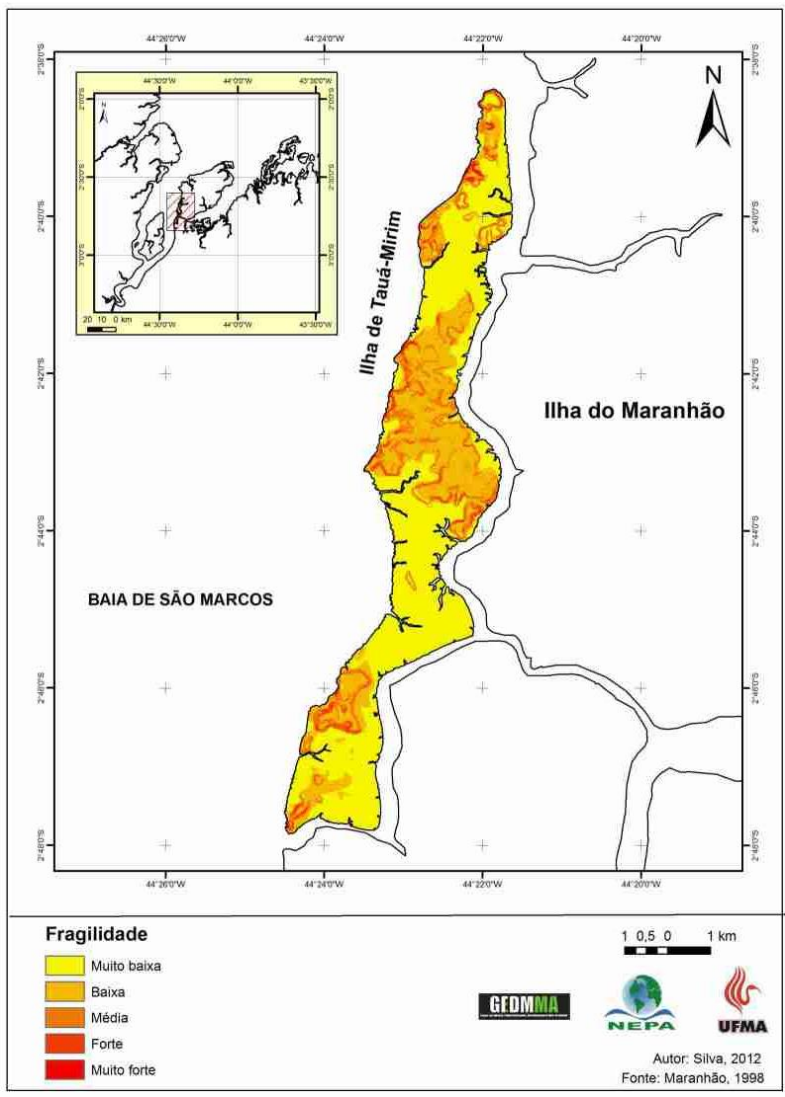

Figura 6 Grau de Fragilidade Fonte: Silva,S.L 


\section{CONSIDERAÇÕES FINAIS}

A análise da fragilidade proposta a partir da concepção sistêmica constituiu um importante instrumento no entendimento da dinâmica natural dos componentes que configuram a paisagem da Ilha de Tauá-Mirim, que se comportam no ambiente com características naturais bastante dinâmicas.

O grau de fragilidade de cada condicionante revelou cenários que tornaram possível a compreensão da real situação da área de estudo, além de deixar evidente que é por intermédio das relações entre os componentes da dinâmica dos fluxos de matéria e energia que a fragilidade potencial da área se mantém estável. Todavia, sua proximidade com o Distrito Industrial de São Luís e o forte adensamento populacional de áreas adjacentes põe em risco tal equilíbrio.

As cartas hipsométrica e de declividade possibilitaram perceber que se trata de uma área extremamente baixa, onde os terrenos estão constantemente sendo afetados pela forte hidrodinâmica local. Também foi possível a identificação de algumas feições morfológicas da área.

Com a carta de solos, foi possível identificar e descrever as classes de solos e suas disposições na área de estudo. Também foi possível perceber a relação direta que estas desempenham no uso das áreas pelas comunidades, e o quanto os solos identificados são frágeis e suscetíveis à erosão, tomando como referência suas características naturais.

A fragilidade apresentada na carta de uso e ocupação/cobertura vegetal, balizada pelas categorias cobertura vegetal, ocupação por núcleos comunitários/caminhos de acesso/áreas de cultivo e solo exposto, demonstrou a importância da expressiva cobertura vegetal da área na manutenção do equilíbrio da paisagem.

Apesar da pequena variação de precipitação em diferentes partes da área de estudo, a condicionante pluviosidade mostrou-se relevante, uma vez que o alto índice pluviométrico da área é capaz de acelerar processos erosivos.

A carta de fragilidade de Tauá-Mirim apresenta as seguintes categorias: fragilidade de grau muito baixa se estendendo por toda área, intercalada por áreas entre baixa e forte que são resultantes da concentração de áreas de solos argissolos e de declividade ente 10 e $20 \%$ e >20\%.

A possibilidade de resguardar a área como reduto protegido na categoria Reserva Extrativista diante das informações observadas em campo, satisfaz as condições estabelecidas em lei para a criação da unidade de conservação, além do que, a analise das classes de fragilidade demonstrou importantes resultados que a área possui na manutenção da dinâmica local, principalmente pela capacidade de proteção desempenhada pela cobertura vegetal, a pequena área de solo exposto e o pouco adensamento populacional. 
Todavia, ao modelo se faz necessário ressaltar que deve ser aprimorado no que diz respeito aos critérios e pesos estabelecidos quando for aplicado em áreas costeiras, principalmente em decorrência da baixa altimetria.

\section{REFERÊNCIAS}

AB'SÁBER,A.N. Contribuição à Geomorfologia do Estado do Maranhão. Notícias Geomorfológicas. Campinas, Departamento de Geografia da UNICAMP, 3(5). ABRIL, 1960.

BERTALANFFY, L. V. Teoria geral dos sistemas. 2. ed. Petrópolis: Vozes, 1975.

BERTRAND, G. Paisagem e geografia física global. esboço metodológico. Revista RA'EGA, 2004 n. 8. Curitiba: 2004.

BEZERRA, J. F. R. Geomorfologia e reabilitação de áreas degradadas por erosão com técnicas de bioengenharia de solos na bacia do rio bacanga, São Luís - MA. Rio de Janeiro: URFJ, 2011. (tese)

BRASIL. Departamento Nacional de Produção Mineral. Programa Levantamentos Geológicos Básicos do Brasil. São Luís. Folha SA. 23-X-C. Estado do Maranhão. Brasília: CPRM, 1994.

RODRIGUES, T. L. N.; et al (Org). Programa de Levantamentos Geológicos Básicos do Brasil: São Luís, Folha AS-23-2-A, Cururupu Folha SA-23-X-C, escala 1:250.000. Brasília: CPRM, 1994.

ROSS, J. L. S. Análise Empírica da Fragilidade dos Ambientes Naturais e Antropizados. In: Revista do Departamento de Geografia, N 8. FFLCH-USP, São Paulo, 1994.

SPÖRL, C. Análise da Fragilidade Ambiental-Relevo-Solo com Aplicação de Três Modelos Alternativos, nas Altas Bacias do Rio Jaguari-Mirim, Ribeirão do Quartel e Ribeirão da Prata. São Paulo: FFLCH/USP, 2001, 165P. (dissertação de mestrado).

Recebido em: 14/08/2016

Aceito para publicação em: 01/10/2016 